\title{
Differential behavior of COVID-19 in Multi-Country Journey: Challenges for Drug Intervention
}

\author{
Archana Gupta* ${ }^{*}$ Anjali Priyadarshini*, Manoj Kumar Yadav, Arpana Vibhuti, \\ V. Samuel Raj, and Ramendra Pati Pandey
}

Centre for Drug Design Discovery and Development (C4D), SRM University, Delhi-NCR, Rajiv Gandhi Education City, Sonepat - 131 029, Haryana, India

*Shared co-first authorship 


\begin{abstract}
:
COVID-19, a pandemic is different as it is in an ongoing phase. We need to understand how the pandemic is developing across the globe. All the existing data and research on the virus are preliminary; researchers are rapidly learning more about new and evolving problems. There is always an underlying mystery that can unfold by studying the available data on this emerging problem and specially to provide an understanding of what can and cannot be said based on this available knowledge. It has been seen that large outbreaks are in China, South Korea, Italy, Iran, Spain, and France, with the US and UK seeing rapidly increasing numbers. But most countries in the world have reported very few to number cases of COVID-19. This is surprising because the trajectory of the COVID-19 outbreak has been said to follow the exposure due to travel, and the areas with low incidence must be having other reasons. The primary factor resulting in the spread of infection is trans country and continent movement of people. The geographical distribution and pattern of COVID 19 infection show a very interesting feature, the tropical countries having a high incidence of Malaria and have undergone the chloroquine regimen show less spike in COVID19 infection. And one of the reasons may be that the virus has not yet reached and started localized transmission in every country, despite these countries having strong travel, migration, or trade relationships with China and the rest of the world. This observation raises various questions. Is the virus not reaching or establishing infections due to some measures taken and the transmission is controlled? The differential behavior of this virus might pose a potential challenge for the development of a suitable intervention that can be useful in all the scenarios.
\end{abstract}




\section{Introduction:}

Researchers are working day and night to find the reasonable explanation for this differential mortality and morbidity rate across different countries. One explanation could be differences in the rate of testing. While it is true that the rate of testing shows a partial positive correlation, and varies a lot among low income, middle income and high-income countries, it is unlikely to account for the whole difference in the recorded case [1]. Another explanation might be related to the differences in social distancing measures implemented across countries. While this is certainly likely to be an important part of the explanation, it is also worth investigating a third possibility. This third possible explanation tries to identify a factor that is common to the group of countries having high mortality due to COVID-19 (US, Spain, Italy, France, Germany, UK), to countries (Bangladesh, Czech, India, Indonesia, Japan, Kenya, Malaysia, Mexico, Nigeria, Pakistan, Sri Lanka, Thailand) having low mortality loads. One hypothesis about such a common factor relates to universal BCG (Bacillus Calmette-Guérin) vaccination [2]. BCG-associated heterologous immunity may be one of the reasons that provides protection against COVID-19 associated mortality [3-6]. The lung environment has an impact on this balance. In this regard, the lung mucosa contains an array of homeostatic components (hydrolytic enzymes, complement proteins, surfactant proteins, antimicrobial enzymes, Igs, and many others) whose function is to maintain homeostasis of the lung [7-8]. Modulation of immune response by BCG is still an under researched phenomenon which needs to be addressed so that its exposure leading to other beneficial effects could be elucidated. Little is known about the role of the lung environment in determining the quality of immune responses generated during Mtb infection and the outcome of active or latent TB disease. The primary function of the lung is gas exchange and thus, the immune response generated within the lung is orchestrated to minimize inflammation. There is a 
delicate balance between generating a massive immune response that will be initially detrimental for the host and Mtb (i.e., cavities in active TB, destroying lung tissue and forcing the bacillus to accelerate replication, and abandon the dying host), or an immune response that will favor both (i.e., granuloma formation in latent Mtb infection, where both host and Mtb live in harmony). Since the immune system is modulated in so many ways by the BCG vaccine which still needs to be researched, populations still undergoing this vaccination are showing fewer spikes in COVID instances may be due to Herd Immunity. Herd immunity refers to a situation where enough people in a population have immunity coming from vaccination or exposure to an infection to be able to effectively stop that disease from spreading. "When about $70 \%$ of the population have been infected and recovered, the chances of outbreaks of the disease become much less because most people are resistant to infection," said Martin Hibberd, a professor of Emerging Infectious Disease at the London School of Hygiene \& Tropical Medicine. "This is called herd immunity. "With the new coronavirus infection -- called COVID-19 -- as more and more people become infected, there will be more people who recover and who are then immune to future infection. Here BCG vaccination may prove to be a game changer giving immunity against Mycobacterium as well as COVID 19. The geographical distribution and pattern of COVID 19 infection shows a very interesting feature, the tropical countries having high incidence of Malaria and have undergone the chloroquine regimen show less spike in COVID19 infection [9-12]. The molecular simulation data (our unpublished data) too suggests that chloroquine has a good binding affinity to the protein present on viral membranes. Chloroquine has also been suggested as a therapeutic and precautionary measure to be taken during this pandemic. Though again how an antiparasitic drug is working against the virus is not known but it gives a great push to repurposing drugs. 


\section{Worldwide spread of COVID-19:}

Now, numerous countries around the world are in the beginning stages of managing their own outbreaks. March 15th, 2020, marked a significant statistical milestone for this, as confirmed cases of COVID-19 outside of China surpassed the Chinese total. The COVID-19 is affecting 210 countries and territories around the world and 2 international conveyances. The number of confirmed cases is lower than the total number of cases. This is due to limiting testing capacity. World reaches more than 18 million Coronavirus Cases with more than lacs of deaths according to European Center for Disease Prevention and Control (ECDC)as on 12 April, 2020. Five countries are responsible for more than $62 \%$ of COVID-19 cases: the U.S., Spain, Italy, France and Germany excluding other countries. Health officials in the U.S. report more cases than any other country at more than 532,879. Their death toll has made a considerable jump this week, and it leads the world in fatalities crossing 20,577 marks. Americans have been warned to expect the situation to grow worse in the coming weeks. Spain is reporting more than 163,027 cases and 16,606 deaths approximately. In Italy, there are more than 152,000 cases. The mortality is second highest, nearly 19, 468, in the world. Germany has the fifth-highest number of confirmed coronavirus infections - more than 125,000. But its death rate is an order of magnitude lower than those in nearby China, UK, Iran etc. Since the situation in the United States has been getting worse day by day, so it deserves an in-depth statistical study in terms of disease progression. New York City and the surrounding suburbs have become the epicenter of the pandemic in the United States, with far more cases than many countries have. More than 181,144 people in the state have found positive for the SARS-CoV-2 virus, with nearly all of them in the city and nearby suburbs. 
Epidemiologists have pointed to New York City's density and its role as an international hub of commerce and tourism to explain why the coronavirus has spread so rapidly. India is the second most populous country in the world with limited healthcare facilities. India has a delayed and light wave of COVID-19 infection compared to the rest of the world. This may be due to early measures taken, or due to limited testing facilities. The total number of reported confirmed cases is more than 8,453 with 972 recovered and 289 deceased as per Indian Government declaration. According to World meter - India has a total 4 confirmed cases, and 0.20 deaths for every 1 million population while the global average is 228 cases and 14 deaths. At first glance, India seems like a coronavirus success story, with its relatively low number of cases and relatively less death rate compared to the rest of the world. But a closer look reveals a grim reality as there are 4 times the rise of COVID-19 cases since the start of this month to till date. This lower-case reporting is also due to limited testing capacity; as of now we have conducted a total 189,111 tests with an average of 137 tests per million Indian population. Our current testing capacity is far below compared to developed countries. A study by disease modelers at the University of Texas at Austin states that "Given the low testing rates throughout the country, we assume that 1 in 10 cases are tested and reported. If any US counties has detected only 1 case of COVID-19, there is a $51 \%$. The chance that there is already a growing outbreak underway COVID-19 is largely spreading undetected, because of the high proportion of asymptomatic and mild infections and limited laboratory testing capacity. Big-city outbreaks dominated the early headlines, and some people in smaller communities thought the social distance naturally built into country living might protect them from the pandemic. Health care systems in rural areas often lack resources and are short on doctors and nurses. 


\section{Case Fatality Rate (CFR) of COVID-19:}

The worldwide comparative study of total confirmed cases and death cases will often provide a clear picture of COVID-19 infection across different countries [13-14]. According to a research, Case Fatality Rate (CFR) is the ratio between confirmed deaths and confirmed cases, and may represent actual fatality rate of COVID-19. This shows comparison of CFR values for COVID19. The total number of confirmed cases of COVID-19 (on the x-axis, going across) versus the total number of deaths (on the y-axis, going up). The grey lines show a range of CFR values where each country lies indicates its CFR - for instance, if a country lies along the $2 \%$ line, its current confirmed cases and death figures indicate it has a CFR of $2 \%$. We have excluded countries which still have a relatively small number of confirmed cases, because CFR is a particularly poor metric to understand mortality risk with a small sample size. The CFR varies by location, and is typically changing over time. CFRs vary widely between countries, from $0.2 \%$ to 14.7\%. Although the US has a CFR of $3.8 \%$ but the total number of deaths are highest compared to France which has a CFR of $14.7 \%$. The CFR of Italy is $12.7 \%$ but here the number of deaths is highest in Europe. CFR is not necessarily an accurate comparison of the true likelihood that someone with COVID-19 will die of it. But if we're careful to acknowledge its limitations, CFR can help us to better understand the severity of the disease and what we should do about it.

The available data for broadly estimating the travel data is the outcome of analysis of various parameters such as travel (inbound and outbound), migration, trade and proximity. Looking at the number of COVID-19 cases in the context of the ranked order of flow of people and goods between China and other countries, the following (as of March 15) is seen. 
Table 1: WTO and Worldometers.info. 2019 Sources: UN, World Bank, Statista, Jeremy

Rossman

\begin{tabular}{|c|c|c|c|c|c|c|c|}
\hline Country & $\begin{array}{c}\text { Inbound } \\
\text { Travel }\end{array}$ & $\begin{array}{c}\text { Outbound } \\
\text { Travel }\end{array}$ & Emigration & Immigration & Export & Import & $\begin{array}{c}\text { Case } \\
\text { Numbers }\end{array}$ \\
\hline S Korea & 1 & 4 & 5 & 18 & 3 & 1 & 8,162 \\
\hline Japan & 2 & 2 & 2 & 7 & 2 & 2 & 814 \\
\hline Russia & 3 & 9 & 18 & 1 & 10 & 9 & 63 \\
\hline USA & 4 & 5 & 1 & 13 & 1 & 3 & 3,083 \\
\hline Mongolia & 5 & & 41 & None & 95 & 44 & 1 \\
\hline Lao, PDR & 6 & & 35 & None & 97 & 71 & 0 \\
\hline Philippines & 7 & & 20 & 16 & 17 & 24 & 140 \\
\hline Singapore & 8 & 6 & 6 & None & 9 & 14 & 226 \\
\hline India & 9 & & 13 & 9 & 6 & 25 & 108 \\
\hline Canada & 10 & & 3 & 8 & 17 & 16 & 255 \\
\hline Thailand & & 1 & 15 & 12 & 16 & 11 & 114 \\
\hline Vietnam & & 3 & 56 & 14 & 4 & 7 & 56 \\
\hline Malaysia & & 7 & 40 & 6 & 13 & 8 & 428 \\
\hline Cambodia & & 8 & 71 & None & 49 & 76 & 7 \\
\hline Indonesia & & 10 & 16 & 15 & 15 & 13 & 117 \\
\hline Italy & & & 7 & None & 19 & 22 & 21,157 \\
\hline UK & & & 8 & 10 & 8 & 20 & 1,372 \\
\hline Bangladesh & & & 9 & 2 & 25 & 81 & 5 \\
\hline Spain & & & 10 & None & 22 & 36 & 7,753 \\
\hline France & & & 11 & None & 20 & 15 & 4,459 \\
\hline Germany & & & 12 & None & 5 & 4 & 5,426 \\
\hline Myanmar & & & 21 & None & 36 & 50 & 0 \\
\hline Korea, DR & & & 23 & None & 76 & 114 & 0 \\
\hline Nepal & & & 31 & None & 111 & 162 & 1 \\
\hline Kazakhstan & & & 63 & None & 35 & 38 & 9 \\
\hline Brunei & & & 66 & None & 96 & 108 & 50 \\
\hline Bhutan & & & 83 & None & 195 & 204 & 1 \\
\hline Pakistan & & & 109 & 3 & 28 & 68 & 5 \\
\hline Kyrgyz Rep & & & 111 & None & 51 & 140 & 0 \\
\hline Tajikistan & & & 134 & None & 101 & 137 & 0 \\
\hline Iran, IR & & & None & None & 31 & 23 & 13,938 \\
\hline Afghanistan & & & None & None & 126 & 161 & 16 \\
\hline
\end{tabular}


This report shows a very lesser number of cases in Russia as compared to Japan, South Korea and the US despite having very strong travel, emigration, immigration and trade relationships with all the mentioned countries. Low incidences have also been seen in various south Asian countries including India and various countries if African subcontinent though they have significant trade and travel relationships with China. One of the reasons may be that the virus has not yet reached and started localized transmission in every country, despite these countries having strong travel, migration or trade relationships with China and the rest of the world. This observation raises various questions. Is the virus not reaching or establishing infections due to some measures taken and the transmission is controlled? [15-18]. Some countries are practicing border control, is it having a positive effect in controlling the COVID-19 menace?

Many countries reporting less incidence belong to the third world or lacking in infrastructures or resources to do mass screening, so is it a case of under screening and under reporting? Is the immunity developed due to exposure of multiple micro-organisms including the malaria parasite and subsequent administration of chloroquine, or the BCG vaccination has a role to play? These vaccines efficiently promoted viral clearance without significant lung damage, mainly through the induction of a $\mathrm{T}$ helper 1 cellular immunity. Is the local climate having an effect on the transmission and spread of COVID-19? The role of median population age? According to the latest data by the Africa Center for Disease Control on COVID-19 in Africa, the breakdown remains fluid as countries confirm cases as and when. The whole of Africa has rising cases with a handful of countries holding out (All statistics are sourced from Africa CDC updates, from the John Hopkins University and from official government data). 
Table 2: COVID-19 cases in South Africa

\begin{tabular}{|c|c|c|}
\hline S.No. & Country & Case Numbers \\
\hline 1 & Algeria & 1,171 \\
\hline 2 & Angola & 8 \\
\hline 3 & Benin & 16 \\
\hline 4 & Botswana & 4 \\
\hline 5 & Burkina Faso & 302 \\
\hline 6 & Burundi & 3 \\
\hline 7 & Cameroon & 509 \\
\hline 8 & Algeria & 1,171 \\
\hline 9 & Angola & 8 \\
\hline 10 & Benin & 16 \\
\hline 11 & Botswana & 4 \\
\hline 12 & Burkina Faso & 302 \\
\hline 13 & Burundi & 3 \\
\hline 14 & Egypt & 985 \\
\hline 15 & Equatorial Guinea & 16 \\
\hline 16 & Eritrea & 22 \\
\hline 17 & Ethiopia & 35 \\
\hline 18 & Eswatini & 9 \\
\hline 19 & Gabon & 21 \\
\hline 20 & Lesotho & 0 \\
\hline 21 & Comoros & 0 \\
\hline 22 & Sao Tome and Principe & 0 \\
\hline 23 & South Sudan & 0 \\
\hline 24 & Lesotho & 0 \\
\hline 25 & Comoros & 0 \\
\hline
\end{tabular}

On the question of whether the low cases are due to a lack of detection or the virus simply not having yet spread to many African countries still unanswered and unlike the virus cases, quarantine numbers aren't being reported which may depict the actual increase in the number of COVID-19 positive patients. 


\section{Summary:}

There are several possible reasons for the low number of cases in many of African countries which may be due to less travel connection, travel restriction imposed, effect of local climate or simply lack of screening. At this stage it is a very difficult task to pinpoint the reason or the reasons for infection containment, but nevertheless each and every variable and the confounding factors need to be addressed and analyzed. Tropical countries encounter a lot of pathogens resulting in infectious diseases. These infectious diseases may mask the milder symptoms of COVID-19 which may go undetected and thus unscreened and unreported. This may result in increase in unreported cases and may lead to an overall increase in these areas. As WHO has stated: "You can't fight a virus if you don't know where it is. Find, isolate, test and treat every case, to break the chains of transmission. Lack of infrastructure and resources is a limiting factor for disease control and hence may create hot spots from where the virus can continually spread. This is a dynamically unfolding pandemic that will require the concerted efforts of counties around the world to control.

\section{Consent for Publication:}

Not applicable

\section{Funding:}

None

\section{Conflict of Interest:}

The author declares no conflict of interest, financial or otherwise.

\section{$\underline{\text { Acknowledgements: }}$}

Declared none 


\section{References:}

1. Miller A, Reandelar MJ, Fasciglione K, Roumenova V, Li Y, Otazu GH. Correlation between universal BCG vaccination policy and reduced morbidity and mortality for COVID19: an epidemiological study. medRxiv. 2020:2020.03.24.20042937.

2. Dayal D, Gupta S. Connecting BCG Vaccination and COVID-19: Additional Data. medRxiv. 2020:2020.04.07.20053272.

3. O'Neill LAJ, Netea MG. BCG-induced trained immunity: can it offer protection against COVID-19? Nat Rev Immunol. 2020;20(6):335-337.

4. Kumar J, Meena J. Demystifying BCG Vaccine and COVID-19 Relationship. Indian Pediatr. 2020;57(6):588-589.

5. Redelman-Sidi G. Could BCG be used to protect against COVID-19? Nat Rev Urol. 2020;17(6):316-317.

6. Sharma AR, Batra G, Kumar M, et al. BCG as a game-changer to prevent the infection and severity of COVID-19 pandemic? [published online ahead of print, 2020 Jul 3]. Allergol Immunopathol (Madr). 2020; S0301-0546(20)30106-3.

7. Nicod LP. Lung defenses: an overview. Eur Respir Rev (2005) 14:45-50. 
8. Hiemstra PS, Bals R. Series introduction: innate host defense of the respiratory epithelium. J Leukoc Biol (2004) 75:3-4.

9. Gutman JR, Lucchi NW, Cantey PT, et al. Malaria and Parasitic Neglected Tropical Diseases: Potential Syndemics with COVID-19? [published online ahead of print, 2020 Jun 1]. Am J Trop Med Hyg. 2020;10.4269/ajtmh.20-0516. doi:10.4269/ajtmh.20-0516.

10. Chiodini J. COVID-19 and the impact on malaria. Travel Med Infect Dis. 2020; $35: 101758$.

11. Smit C, Peeters MYM, van den Anker JN, Knibbe CAJ. Chloroquine for SARS-CoV-2: Implications of Its Unique Pharmacokinetic and Safety Properties. Clin Pharmacokinet. 2020;59(6):659-669.

12. Gao J, Tian Z, Yang X. Breakthrough: Chloroquine phosphate has shown apparent efficacy in treatment of COVID-19 associated pneumonia in clinical studies. Biosci Trends. $\quad$ 2020;14(1):72-73. doi:10.5582/bst.2020.01047

13. Lazzerini, M., \& Putoto, G. (2020). COVID-19 in Italy: momentous decisions and many uncertainties. The Lancet Global Health. 
14. Onder G, Rezza G, Brusaferro S. Case-Fatality Rate and Characteristics of Patients Dying in Relation to COVID-19 in Italy. JAMA. Published online March 23, 2020.

15. Chu DK, Akl EA, Duda S, et al. Physical distancing, face masks, and eye protection to prevent person-to-person transmission of SARS-CoV-2 and COVID-19: a systematic review and metaanalysis. Lancet. 2020;395(10242):1973-1987.

16. Hellewell J, Abbott S, Gimma A, et al. Feasibility of controlling COVID-19 outbreaks by isolation of cases and contacts [published correction appears in Lancet Glob Health. 2020 Mar 5;:]. Lancet Glob Health. 2020;8(4):e488-e496.

17. Ferretti L, Wymant C, Kendall M, et al. Quantifying SARS-CoV-2 transmission suggests epidemic control with digital contact tracing. Science. 2020;368(6491).

18. Garcia Godoy LR, Jones AE, Anderson TN, et al. Facial protection for healthcare workers during pandemics: a scoping review. BMJ Glob Health. 2020;5(5). 